\title{
Petrol-Su Ayrışma Sistemlerindeki Birleştirilmiş Plakaların Ayrıșma Verimliliği Üzerindeki Etkisinin Deneysel Olarak İncelenmesi
}

\author{
Mehmet Oruç ${ }^{1}$, Sedat Yayla ${ }^{2 *}$ \\ Geliş / Received: 11/12/2019 \\ Revize / Revised: 10/02/2020 \\ Kabul / Accepted: 11/02/2020 \\ ÖZ \\ Petrol-su ayrışma sistemleri, sudan arındırılmış petrol elde edilmesi açısından önem taşımakla birlikte suya olan \\ ihtiyacın arttığı günümüz koşullarında ayrışmış suyun da elde edilmesi önem taşımaktadır. Bu çalışma, petrol-su \\ karışımlarının ayrıştırılması sistemlerinde yaygın olarak kullanılan delikli birleştirilmiş plakalar ile \\ gerçekleştirilen bir dizi çalışma içermektedir. Farklı özelliklere sahip petrol-su karışımları üç farklı petrol \\ sahasından alınarak ayrışma sistemine farklı hız değerlerinde $(0.5,0.7,0.9 \mathrm{~m} / \mathrm{s})$ pompalanmıştır. Deneysel olarak \\ yapılan bu çalışmada ölçümler $25^{\circ} \mathrm{C}$ 'de gerçekleştirilmiştir. Deney sonucunda elde edilen ayrışmış suyun \\ içindeki petrol oranı ölçülerek ayrışma verimlilik değerleri belirlenmiştir ve her bir numunenin üç farklı Re \\ sayısı için petrol-su karışımının ayrışma verimliliği incelenmiştir. Elde edilen ayrışma verimlilik değerleri ile \\ karışımın sisteme pompalanma hızı arasındaki ilişki irdelenip yorumlanmıştır. Yapılan deneyler ve analizler \\ sonucu elde edilen ayrışma verimlilik değerinin Re sayısı ile orantılı olarak belli bir noktaya kadar arttığı daha \\ sonra ise akış karakteristiklerinden ve uygulanan birleştirilmiş plaka geometrisinden dolayı düştüğü \\ gözlemlenmiştir. En iyi ayrışma verimlilik değeri 2660,76 Re sayısında, başlangıçta $\% 11$ petrol içeren petrol-su \\ karışımının kullanılmasıyla; ayrışan suda $\% 0.5$ petrol oranının ölçülmesi ile elde edilmiştir.
}

Anahtar Kelimeler- Petrol-Su Ayrıştırılması, Delikli Birleştirilmiş Plakalar, Stokes Kanunu, Yerçekimsel Ayrışma, Atık Suyun Ayrıştırılması

\footnotetext{
1 mehmetoruc@yyu.edu.tr (ORCID: 0000-0001-7497-7613)

Makine Mühendisliği, Van Yüzüncü Yıl Üniversitesi, 65080, Kampüs / VAN

$2 *$ Sorumlu Yazar Sedat YAYLA: syayla@yyu.edu.tr (ORCID: 0000-0001-6640-6511)

Makine Mühendisliği, Van Yüzüncü Yıl Üniversitesi, 65080, Kampüs / VAN
} 


\title{
Experimental Investigation of Effect on Coalescing Plates in Oil- Water Separation Systems on Separation Efficiency
}

\begin{abstract}
Despite oil-water separation systems are important for obtaining separated oil from water, it is also important to obtain decomposed water in today's conditions where the need for water increases. This study includes a series of studies performed with corrugated coalescing plates commonly used in the separation of oil-water mixtures. Oil-water mixtures with different properties were taken from three different oil fields and pumped to the separation system at different speed values $(0.5,0.7,0.9 \mathrm{~m} / \mathrm{s})$. In this experimental study, measurements were performed at $25{ }^{\circ} \mathrm{C}$. The separation efficiency values were determined by measuring the oil content in the dissolved water obtained from the experiment and the decomposition efficiency of the oil-water mixture was examined for three different Re numbers of each sample. The relationship between the separation efficiency values obtained and the pumping rate of the mixture into the system was examined and interpreted. It was observed that the separation efficiency value obtained as a result of the experiments and analyzes increased up to a certain point in proportion with the number of $\mathrm{Re}$, and then decreased due to the flow characteristics and the coalescing plate geometry applied. The best separation efficiency value is $2660.76 \mathrm{Re}$, using an oil-water mixture initially containing $11 \%$ oil; It was obtained by measuring the $0.5 \%$ oil content in the separated water.
\end{abstract}

Keywords- Oil-Water Separation, Corrugated Coalescing Plates, Stokes Law, Gravitational Separation, Waste Water Treatment 


\section{GİRIŞ}

Yer altından çıkarılan kuyu akışkanları genelde temiz su, petrol ve gaz bileşenlerinin karışımı olup bu akışkanların her birinin ait olduğu sektörde kullanılabilmesi için belli işlemlerden geçirilmesi gerekmektedir. Ham petrol veya gaz; yeraltı suyu, çamur, katı parçacıklar ve bir miktar da çıkarılan kayacın özelliklerine göre değişiklik gösterebilen kimyasal madde içerir. Bahsedilen bu maddelerin karışımı halinde yeryüzüne çıkarılan ürünlerin kullanılabilmesi için ilk olarak ayrıştırma sürecinden geçirilmesi gerekmektedir. Petrol elde edilme endüstrisinde; üretilen su, atık akışkanlarının en büyük kısmını oluşturur ve suyun petrole oranı yaklaşık olarak 3: 1'dir [1]. Petrol ve gazın yeraltı haznesinden üretilmesinin bir sonucu olarak atık su (yeraltı suyu) sorunu meydana gelir [2]. Dünyada üretilen suyun ortalama olarak 200 milyon varil/gün civarında olduğu değerlendirilir [3]. Petrol üretim işlemi sırasında çıkarılan su aşırı bir şekilde artar ve petrol üretimi boyunca bu artış sabit kalmaz. Bu durum, su ve petrol üretimi arasında negatif bir korelasyon olduğunu destekler [4]. Uzun süredir üretim yapılan petrol sahalarında su oranı $\% 90^{`}$ dan fazla olabilir $[1,3]$. Küreselleşmeyle birlikte, son günlerde su üretim miktarında artış beklenmektedir ve bu suyun ekosistemde yer almasının ciddi bir endişe oluşturacağ belirtilmektedir [1].

Üretilen ve yeryüzüne çıkartılan su; gaz ve ham petrol içerdiği için kirlidir bu yüzden de içme ve sulama için kullanılamaz ve petrol üretim sürecinde de en büyük atık genellikle sudur [4-6]. Bu atık akışkan karışımı ya gazlı hidrokarbon ya da yerleşmiş kum veya kil maddeleri içerir [7]. Yeryüzüne çıkartılan sudaki yüksek toksin miktarı ve çözünürlüğünden dolayı insanlık için ciddi bir çevresel sorun teşkil eder [8]. Hidrokarbonların kanser ve diğer ciddi rahatsızlıkların riskini artırdığı U.S. çevre koruma derneği uyarınca belirtilmiştir [9]. Bu yüzden ilgili materyallere maruz kalmayı en aza indirmek, insan ve sudaki hayatı korumak için büyük önem taşımaktadır [10].

Üretilen sudan petrolün ayrıştırılması için çeşitli ayrıştırma yöntemleri bulunmaktadır. Yerçekimsel ayrıştırma da bu yöntemlerden biri olup uzun zamandan beri kullanılmaktadır [11]. Çeşitli çalışmalar ile savunulan bu sistem yerçekimi etkisi ile farklı yoğunluklara sahip malzemelerin ayrıştırılmasını içeren tüm uygun faz ayrıştırma tekniklerini tanımlar. Yerçekimi etkisiyle kullanılan petrol üretim metodu kapsamında üretilen suyun ayrıştırılması için geniş ve çeşitli uygulamalar mevcuttur. Yerçekimi sistemi ekonomik olarak faydalıdır ve yer çekimi tekniği petrolün ayrıştırılması için en çok kullanılan tekniktir [11-14].

Morrison, birleştirilmiş plaka kullanılarak yapılan ayrıştırma sisteminin faydalarını; API sistemi içermesinin yanı sıra, petrol ayrıştırmasını arttırmak, plakalar içinde laminar akış sağlamak, verimli akış dağılımı, kendi kendini temizleyebilme, petrol çamurunu rahat bir şekilde yeryüzüne çıkarma, sıkıştırılabilir özellikte ve düşük maliyetli olması olarak belirtmiştir [15]. Bu sistemin zayıf yönü ise tıkanabilmesi ve levhaların üzerinden petrol veya su akma potansiyelinin olmasıdır.

Kok ve Marson, delikli plaka ayrıştırıcısı hacminin, daha fazla yerçekimi sistemine olan ihtiyacını azaltıp petrol damlacık hareketlerini önlemek için bu hacmin azaltılması gerektiğini açıklamışlardır [16]. Hacim azaltılmasının ise sisteme daha fazla delikli levha yerleştirilmesi ile mümkün olacağını belirtmişlerdir. Mohr, sistemin katı parçacıklarla tıkanması ve delikli plaka önleyicileri gibi konularda iyileştirmeler yapmak için farklı tasarımların geliştirildiğini açıklamıştır ve kendi yaptığı çalışmalarda da tasarımı farklı birleştirilmiş levhaları kullanmıştır [17]. Kullanılan bu tip ayrıştırma sistemi sayesinde düşük Reynolds sayısı ile elde edilecek laminar akışla düşük yoğunluklu petrol ayrıştırılıp sistemden dışarıya su akışı elde edilebilmektedir.

Kuyudan çıkartılan karışımın ilk olarak barındırdığı katı parçacıklardan ayrıştırılması için I. Proses denilen ayrıştırma işlemine tabi tutulur. Barındırdığı katı parçacıklardan arındırılan karışım II. Prosese tabi tutulup içerdiği sudan ayrıştırılır. Ham petrolün içindeki suyun ayrıştırılması için geliştirilen çeşitli yöntemler mevcuttur. Petrolün sudan ayrıştırılmasının en kolay yollarından biri yerçekimi kuralına göre daha ağır olan akışkanın dibinde birikeceği bir tank kullanmaktır. Yoğunluğu petrolden daha ağır olan su, tankın daha alt kısmına çökerken petrol tankın üst kısmında kalmaktadır. Bu nedenle petrol daha fazla işleme tabi tutulmadan ya ayrıştırılır ya da rezervuar tankına gönderilir. Sonuç olarak petrolün boru hattına gönderilmeden önce suyun petrolden çıkarılma işlemi gerekli ve önemlidir [18]. Petrol endüstrisinde suyun petrolden ayrıştırılma süreci çeşitli sorunlar içermektedir. Petrol üretimini arttırmak amacıyla gaz ve petrol şirketleri karışımdaki su miktarını 
azaltmak için sürekli daha etkili yöntemler arayışında olmuşlardır. 18. Yüzyıldan bu yana yeraltı suyu, su ve petrol karışımı olarak üretilmektedir. Sonraki yıllarda daha büyük ve yeni su arıtma tesisleri inşa edilirken; stok rezervuar montajı, petrolsüz çukur, petrol varil ayrımı gibi farklı ayrıştırma metotları geliştirilmiştir. Geçmişte, petrol ve gazın ayrıştırılması amacıyla akışkanlar ayrıştırma tankına aktarılırdı ve kalan suyun daha fazla ayrıştırılması için su, arıtma tesisinden bütün süreç boyunca geçirilirdi. Escobar ve Guerin, yapmış oldukları çalışmalarda birleştirilmiş delikli plaka ayrıştırıcısının gravite ayrıştırma sisteminin ana oluşumlarından biri olduğunu belirtmişlerdir $[19,20]$. Bu aparatlar, farklı yoğunluktaki petrol ve suyu standart ayrıştırma metodu biçiminde ayrıştırmak için kullanılır. Birleştirilmiş plaka sistemli ayrıştırmanın prensibi; petrol kabarcıklarının yukarı doğru çıkıp birleşmesine, daha büyük hacim değerlerine ulaşmasına ve bu büyük hacimli petrol damlacıklarının daha kolay bir şekilde ayrıştırılmasına olanak sağlamaktır. Birleştirilmiş delikli plaka sisteminin ayrıştırma performansı uygun bir dizayn ile daha da geliştirilebilir. Simetrik delikli plaka sistemi olarak tasarlanan bir ayrıştırıcı, geçmişte de kullanılan bir gravite ayrıştırıcı tekniği ile benzerlik göstermektedir. Bu sistemin etkinliği, separator havza büyüklügünü arttırmaya gerek kalmadan sistemin içine paralel levhaların yerleştirilmesiyle arttırılabilir. Sedat Yayla ve ark., petrol ve suyun ayrıştırılması üzerine birleştirilmiş plakalar kullanarak sayısal bir çalışma yapmışlardır [21]. Yaptıkları çalışmada yatay birleştirilmiş plaka kullanarak plakalar arası mesafe ve petrol-su karışımının sisteme giriş hızlarını değiştirerek optimum verimi analizleri yapmışlardır.

Bu çalışma kapsamında da Adıyaman, Batman ve Diyarbakır illerindeki tesislerden temin edilen, I. Prosesten geçirilmiş ham petrol numuneleri (içindeki katı partikül ve suyun bir kısmından ayrıştırılan ham petrol) farklı hız değerlerinde ayrışma sistemine aktarılıp ayrışma verimliliği deneysel olarak incelenmiştir. 3 farklı numuneye ait yoğunluk, viskozite değerleri göz önünde bulundurulup petrol-su karışımının sisteme giriş hızı arasındaki değişim ile ayrışma verimliliği arasındaki bağlantı deneysel olarak irdelenmiştir.

\section{MATERYAL ve METOD}

Ayrışma verimliliği ve petrol-su karışımının ayrışma sistemine pompalanma hızı arasındaki ilişki deneysel olarak incelenmiş olup, sisteme giren ve sistemden ayrışmış bir şekilde çıkan tüm akışkanların reolojik özellikleri de ölçülüp ilgili hesaplamalarda kullanılmıştır. Adıyaman, Batman ve Diyarbakır'daki petrol sahalarından temin edilen; I. Prosesten geçirilmiş petrol-su karışım numunelerinin viskozitesi, yoğunluğu ve petrol oranı ölçülüp tablo 1 'de belirtilmiştir.

Tablo 1. Petrol-Su karıșımlarının özellikleri.

\begin{tabular}{|c|c|c|c|}
\hline \multicolumn{5}{|c|}{ Tablo 1. Petrol-Su karışımlarının Özellikleri. } \\
\hline Numune No & Karışımdaki Petrol Oranı (\%) & Yoğunluk (kg/m $\mathbf{3})$ & Viskozite (Pa.s) \\
\hline Numune 1 & 9 & 785 & $6.4 \times 10^{3}$ \\
\hline Numune 2 & 10 & 805 & $6.1 \times 10^{3}$ \\
\hline Numune 3 & 11 & 853 & $5.7 \times 10^{3}$ \\
\hline
\end{tabular}

Petrol-su karışımının viskozitesi sıcaklık kontrollü viskozimetre ve yoğunluğu ise el tipi yoğunluk ölçer ile ölçülmüştür. İlgili ölçüm cihazları şekil 1'de gösterilmektedir. Karışımı sisteme aktaran boruların iç çapı 1 parmak (inç) olup $25.4 \mathrm{~mm}$ 'dir. İlgili Reynolds sayısının hesaplanmasında boru iç çapı $25.4 \mathrm{~mm}$ olarak ele alınmıştır. Akışkan karışımının ayrışma sistemine girmeden önceki ve girdikten sonraki yoğunluk değerleri ölçülüp karışım yoğunluğunun değişimi de irdelenmiştir. Karışımın petrol/su oranı ise sıcaklık kontrollü manyetik karıştırıcı ile hesaplanmıştır. 55C 'ye kadar ssıtılan numuneler 1000 rpm değerinde 5 dakika boyunca döndürülmüştür. Bu süre içinde belli bir sıcaklık değerine ulaşan petrol damlacıkları uygulanan döndürme kuvveti sayesinde birbirine yapışmakta olup hacmi artan petrol damlacıkları da yoğunluk farkından dolayı karışımın yüzeyine çıkmıştır. 100 ml'lik mezürde yapılan bu işlem sonucunda petrolde bulunan tüm petrol damlacıkları yüzeyde birikip sudan ayrışmıştır. Mezürdeki petrol ve su oranı gözle görülecek seviyeye geldiğinden ilgili değer okunup yazılmıştır. 


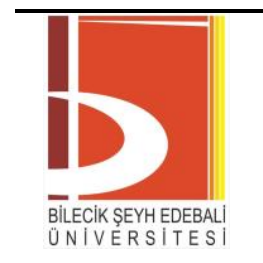

BŞEÜ Fen Bilimleri Dergisi

7. Cilt - Milli Mücadele ve TBMM'nin

BSEU Journal of Science

Açılışının 100. Yı1ı Anısına-100. Yıl Özel

DOI: 10.35193/bseufbd.658231

Sayıs1

163-174, 2020

e-ISSN: 2458-7575 (http://dergipark.gov.tr/bseufbd)
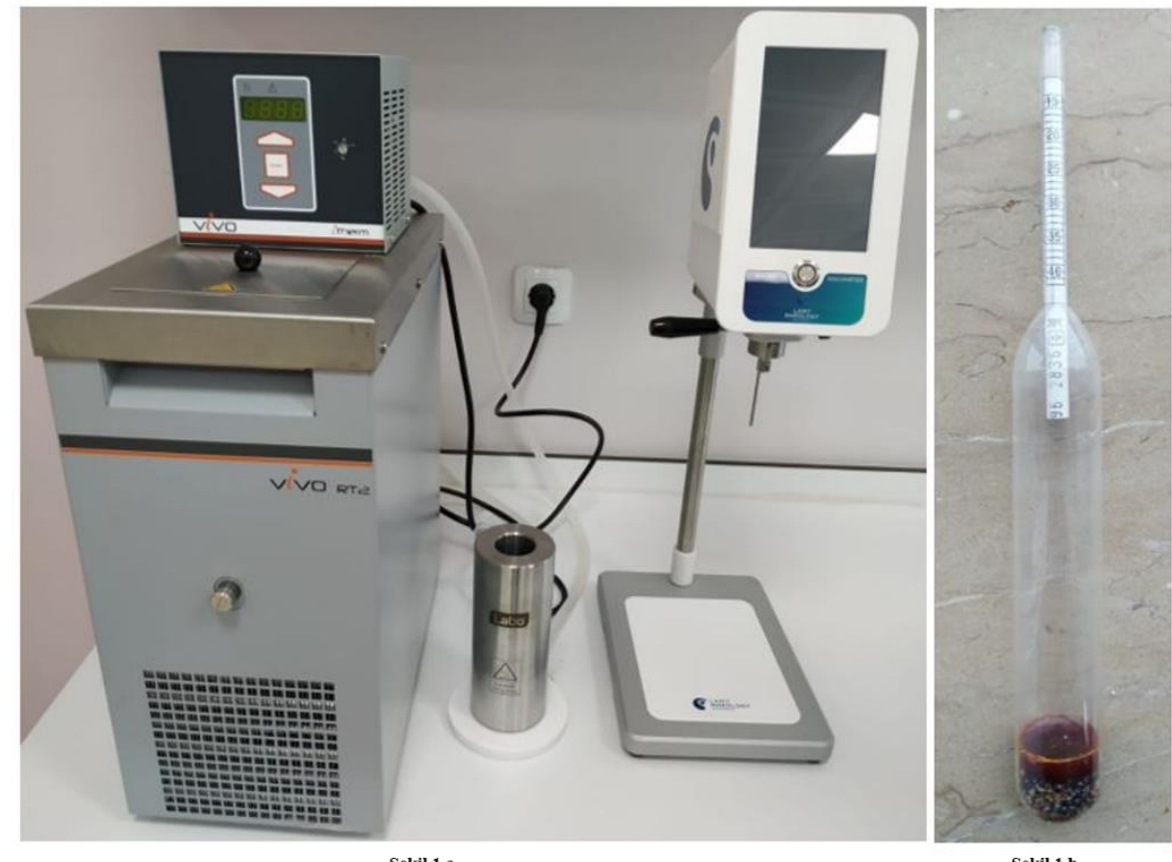

Șekil 1 a

Şekil 1 b

Şekil 1. Ölçümlerde kullanılan Viskozimetre ve El Tipi Yoğunluk Ölçer; 1a: Sicaklık Kontrollü Viskozimetre 1b: El tipi yoğunluk ölçer

Adıyaman, Batman ve Diyarbakır'da bulunan sahalardan alınan petrol-su karışımının viskozitesi LAMY RM 100 viskozimetre kullanılarak ölçülmüştür. Sicaklık kontrollü viskozimetre ile, hangi sıcaklık değerinde deneyler gerçekleştirilmişse alınan numuneler de aynı sıcaklık değerinde tutulup viskozite ölçümü yapılmıştır. Çalışma kapsamında kullanılacak petrol numuneleri temin edilip reolojik özellikleri belirlendikten sonra ilgili deneyler yapılmaya başlanmıştır. Deneysel çalışmada kullanılan ayrışma sistemi şekil 2a'da ayrışma süreci boyunca gerçekleşen tüm adımların iş akış diyagramı ise şekil 2b'de gösterilmektedir.

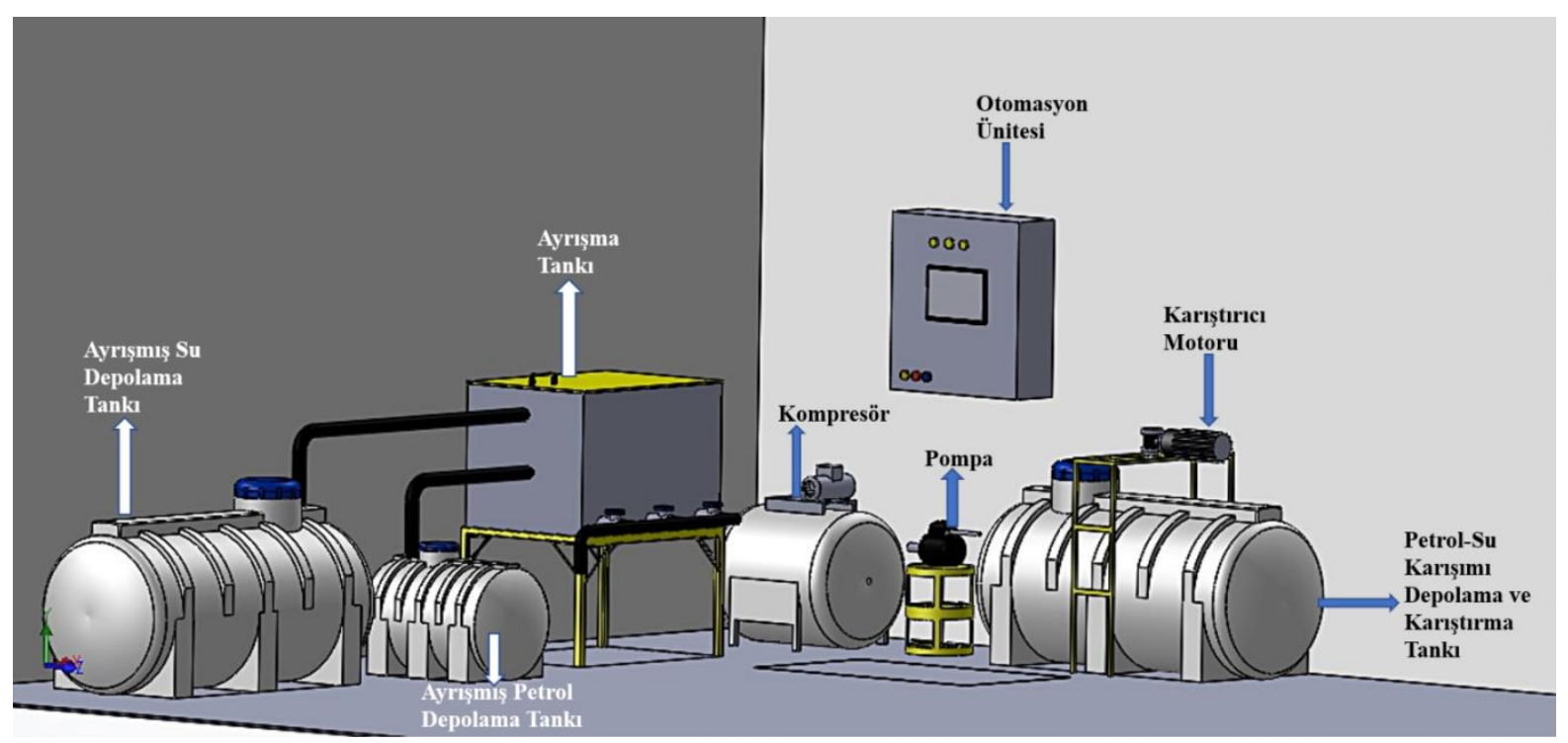

Şekil 2a. Deney Düzenek Şeklinin Genel Hali 


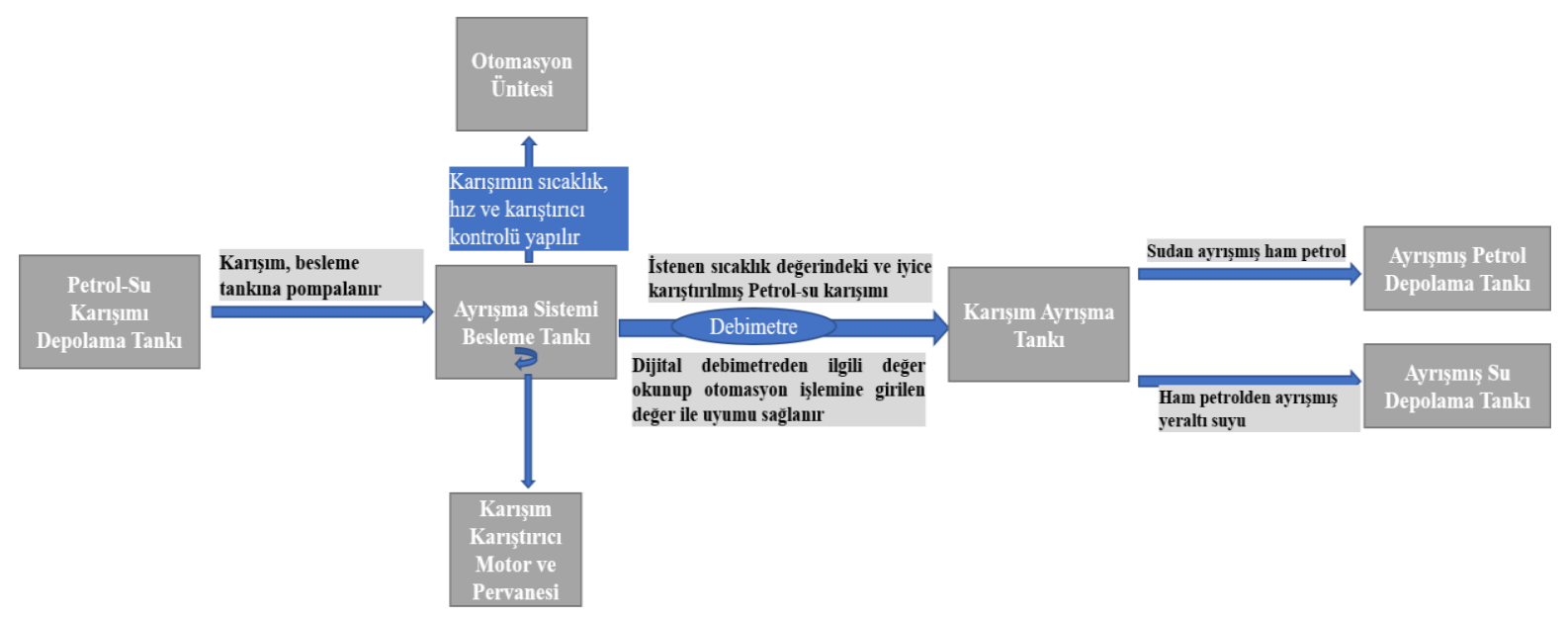

Şekil 2b. İş Akış Diyagramı

Şekil 1.'de görüldüğü gibi petrol-su karışımı bir pompa yardımıyla ayrıştırma sistemine aktarılmaktadır. Sisteme girecek olan karışımın hızı da kademeli pompa ile ayarlanıp istenilen hızlarda sisteme akışkan pompalanmaktadır. Sistemde HP10 Metalik Gövdeli Diyaframlı Pompa kullanılmış olup otomasyon ünitesinden debi kontrolü yapılmışıı. Sistemin çıkışında debimetre bulunmaktadır ve böylece karışımın sistemden çıkış hız değerleri de ölçülebilmektedir. Birleştirilmiş plakalardan geçirilen ve bu sürede de ayrışan petrol, yoğunluğunun sudan daha düşük olması sebebiyle petrol-su karışımın üstünde bir tabaka olarak (film şeklinde) birikecek olup bu petrol tabakası da ayrıştırılmış petrol tahliye vanası ile tahliye edilecektir. İçinde kısmen de olsa petrol bulunan su ise su tahliye vanası ile tahliye edilecektir.

Deneylerde kullanılan ayrışma sistemi besleme tankı, 2000 litre kapasitede olup Polietilenden üretilmiştir. Aynı zamanda yüksek sıcaklık değerlerine ve darbelere karşı dayanıklıdır. İlk olarak petrol-su karışımı besleme tankında 30 dakika süreyle karıştırıcı ile karıştırılmıştır. Yapılan bu karıştırma işlemi sayesinde karışımın homojenliği sağlanmış olup ayrışma sistemine pompalanmaya hazır hale gelmiştir. Diyaframlı pompaKompresör (4000 lt kapasiteli) setinin çalışması ve kurulan otomasyon ünitesi ile karışımın hızı ayarlanıp istenilen hız değerlerinde karışım sisteme pompalanmıştır. İlgili tüm deneylerde karışımın sıcaklı̆̆ 1 da aynı şekilde kurulan otomasyon sistemi ile sabit tutulup $25^{\circ} \mathrm{C}$ 'de gerçekleştirilmiştir. Tüm deneylerin $25^{\circ} \mathrm{C}^{\prime} \mathrm{de}$ yapılmasının nedeni; sahada II. Proses kapsamında gerçekleştirilen çalışmalar $20-30{ }^{\circ} \mathrm{C}$ aralığında değişen sıcaklık değerlerinde gerçekleştirilmektedir. Sıcaklık bandının biraz geniş olmasının nedeni yaz-kış mevsiminde farklılık göstermesidir. Gerçekleştirilen çalışmaların sahadaki gerçek verilerle uygunluk gösterebilmesi için sicaklık değeri $25^{\circ} \mathrm{C}$ 'de sabit tutulmuştur.

Deney düzeneğinde kullanılan ayrışma tankı metal olup paslanmaması için kaplanıp boyanmıştır. Kapasitesi 2500 litre olan ayrışma tankının dibinde; çöken katı parçacıkların tahliyesi için vanalar bulunurken, alt tarafında ise ayrışmış su tahliye vanası bulunmaktadır. İlgili tankın üst noktalarına monte edilen vana sayesinde de ayrışıp yüzeye biriken ham petrol tahliyesi sağlanmıştır. Ayrışan su ve ham petrol bu tahliye vanaları aracılığıyla ayrışmış su ve ayrışmış petrol depolarına tahliye edilmiştir. Ayrışmış su depolama tankı 2000 litre kapasitede iken ayrışmış petrol depolama tankı 500 litre kapasiteye sahiptir. Ayrışma sisteminde kullanılan birleştirilmiş plakaların özellikleri tablo 2'de verilmiştir ve özellikleri belirtilen delikli birleştirilmiş plakalar kullanılarak kurulan setler aracılığıyla ayrışma sağlanmış olup ilgili tüm deneyler gerçekleştirilmiştir.

Tablo 2. Deneylerde kullanılan birleştirilmiş plakaların özellikleri.

\begin{tabular}{|l|l|}
\hline Birleştirilmiş Plaka Uzunluğu (mm) & $800 \mathrm{~mm}$ \\
\hline Birleştirilmiş Plaka Delik Çapı (mm) & $11 \mathrm{~mm}$ \\
\hline Birleştirilmiş Plakalar Arası Mesafe (mm) & $24 \mathrm{~mm}$ \\
\hline
\end{tabular}




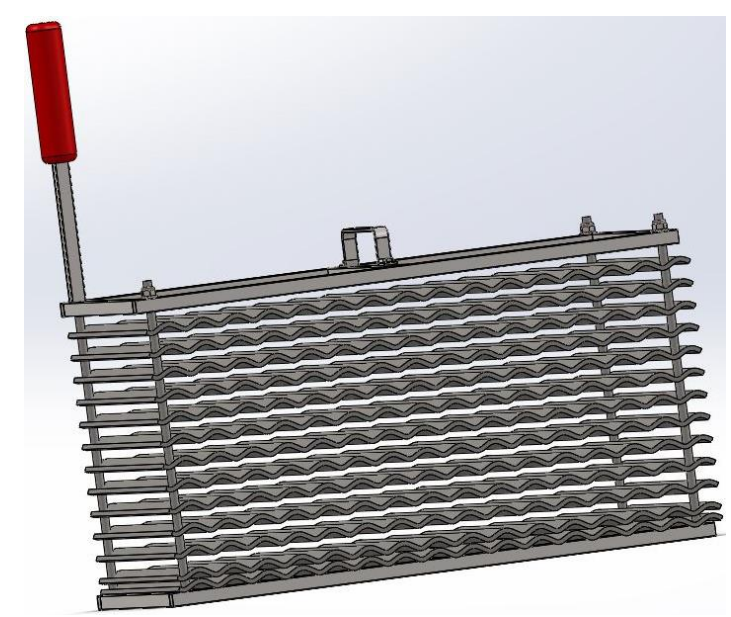

Şekil 3. Ayrışma sisteminde kullanılan birleştirilmiş plakalar seti

Şekil 3'de de görüldüğü üzere ayrışma sistemine pompalanan petrol-su karışımı; delikli birleştirilmiş plakalardan oluşan setlerden geçirilerek ayrışma sağlanmaktadır. Delikli birleştirilmiş plaklardan geçirilen karışımın içinde bulunan petrol damlacıkları birbirine yapışıp yüzeyde film şeridi gibi toplanmaktadır. Ham petrolün yoğunluğu suyun yoğunluğundan daha düşük olduğundan ayrışan su da ayrışma tankının dibinde toplanmaktadır. Birbiri içinde çözünmeyen akışkanların yoğunluk farkından faydalanarak ayrıştırılması ve yoğunluğu düşük olan petrol damlacıklarının yüzeyde birikmesi Stokes Kanunu'na göre meydana gelmiştir.

Petrol kürecikleri Stokes yasasının laminer akış şartlarına bağlı olarak yukarı doğru hareket etmeye devam edecektir. Parçacıkların boyutunun artışı laminer akış hızının yükselmesine yol açar. Ayrıştırıcıların gerekli boyutlarını hesaplayabilmek için petrol kabarcıklarının hız artışını bilmek büyük önem taşır. Petrol ayrıştırma sisteminin boyutları hesaplanırken, petrol kabarcıklarının serbest hale gelebilmesi için, birbirine bağlı iki sistemden birinin çıkışının diğer sistemin girişine uygun olması göz önünde bulundurulur. Suyun petrol küreciklerini sistemin diğer tarafına itmesinden önce petrol küreciklerinin en dipten yüzeye hareket edebilmeleri için yeterli zaman verilmelidir.

Aşağıdaki denklem Stokes yasasını tanımlamaktadır [22].

$$
\mathrm{Vp}=\left(\frac{\mathrm{G}}{\mathrm{Ig} * \mathrm{p}}\right) *(\mathrm{dp}-\mathrm{dc}) * \mathrm{D}^{2}
$$

Bu denklemde

$$
\begin{aligned}
& \mathrm{Vp}=\text { hız, cm/sec. } \\
& \mathrm{G}=\text { yerçekim ivmesi, } 980 \mathrm{~cm} / \mathrm{sec} 2 . \\
& \mu=\text { bulk fazının viskozitesi. } \\
& \mathrm{dc}=\text { bulk fazının yoğunluğu, gm/cm3. } \\
& \mathrm{dp}=\text { kürecik fazının yoğunluğu, gm/cm3. } \\
& \mathrm{D}=\text { kürecik çapı, } \mathrm{cm} .
\end{aligned}
$$


Tüm ölçümleri yapılan petrol numunelerinin Reynolds Sayıları hesaplanmış olup Re sayısı ile ayrışma verimliliği arasındaki ilişki bu çalışma kapsamında irdelenmiştir.

- $R e=\frac{\rho \cdot U_{1} D}{\mu}$

Re: Reynolds Sayısı

$\rho$ : Petrol-su karışımın yoğunluğu( $\left.\mathrm{kg} / \mathrm{m}^{3}\right)$

$\mathrm{U}_{1}$ : Petrol-su karışımının ayrışma sistemine giriş hızı $(\mathrm{m} / \mathrm{s})$

D: Petrol-su karışımını ayrışma sistemine taşıyan borunun çapı $(\mathrm{m})$

$\mu$ : Petrol-su karışımının dinamik viskozite değeri $(\mathrm{kg} / \mathrm{m} . \mathrm{s})$

Reynolds Sayısı hesaplamaları ve çalışma kapsamında gerçekleştirilen deneyler tablo 3'de görülmekte olup ayrışma verimliliği ile Reynolds sayısı arasındaki ilişki incelenip tüm veriler bu doğrultuda sentezlenmiştir.

Tablo 3. Re Sayısı hesaplamasında kullanılan değerler.

\begin{tabular}{|c|c|c|c|c|c|}
\hline & Yoğunluk $\left(\mathrm{kg} / \mathrm{m}^{3}\right)$ & $\begin{array}{c}\text { Hiz } \\
(\mathrm{m} / \mathrm{s})\end{array}$ & $\begin{array}{c}\text { Boru Çapı } \\
(\mathrm{m})\end{array}$ & $\begin{array}{c}\text { Viskozite } \\
\text { (Pa.s) }\end{array}$ & Re Sayısı \\
\hline \multirow{3}{*}{ Numune 1} & \multirow{3}{*}{785} & 0.5 & \multirow{3}{*}{0.0254} & \multirow{3}{*}{$6.4 \times 10^{-3}$} & 1557,73 \\
\hline & & 0.7 & & & 2180,82 \\
\hline & & 0.9 & & & 2803,92 \\
\hline \multirow{3}{*}{ Numune 2} & \multirow{3}{*}{805} & 0.5 & \multirow{3}{*}{0.0254} & \multirow{3}{*}{$6.1 \times 10^{-3}$} & 1675,98 \\
\hline & & 0.7 & & & 2346,37 \\
\hline & & 0.9 & & & 3016,77 \\
\hline \multirow{3}{*}{ Numune 3} & \multirow{3}{*}{853} & 0.5 & \multirow{3}{*}{0.0254} & \multirow{3}{*}{$5.7 \times 10^{-3}$} & 1900,54 \\
\hline & & 0.7 & & & 2660,76 \\
\hline & & 0.9 & & & 3420,97 \\
\hline
\end{tabular}

\section{BULGULAR ve TARTIŞMA}

İlgili deneyler $800 \mathrm{~mm}$ uzunluğuna, $11 \mathrm{~mm}$ delik çapına ve $24 \mathrm{~mm}$ plaklar arası mesafeye sahip birleştirilmiş plakalardan oluşan set ile gerçekleştirilmiştir. Gerçekleştirilen tüm deneyler sırasında sıcaklık sabit ve $25^{\circ} \mathrm{C}$ 'de iken gerçekleştirilmiştir. Deney boyunca sıcaklık değeri otomasyon kontrol ünitesinden kontrol edilerek sabit tutulmuştur.

Çalışma kapsamında gerçekleştirilen deneylerde ayrışmış su depolama tankına su akışı başladıktan sonra her 15 dakikada bir $100 \mathrm{ml}$ numune alınıp ilgili deney sonuna kadar toplanan tüm numunenin sonucuna göre ayrışma verimlilik değeri bulunmuştur. Çalışma kapsamında gerçekleştirilen deneyler tablo 5'de gösterilmiştir.

Tablo 4. Gerçekleştirilen deneyler.

\begin{tabular}{|c|c|c|c|}
\hline Numune No & $\mathbf{R e}_{\mathbf{1}}$ & $\mathbf{R e}_{\mathbf{2}}$ & $\mathbf{R e}_{\mathbf{3}}$ \\
\hline Numune 1 & 1557,73 & 2180,82 & 2803,92 \\
\hline Numune 2 & 1675,98 & 2346,37 & 3016,77 \\
\hline Numune 3 & 1900,54 & 2660,76 & 3420,97 \\
\hline
\end{tabular}

Deney süresince alınan her bir numune, deney sonrasında $55^{\circ} \mathrm{C}^{\prime}$ ye kadar 1 sitılıp $1000 \mathrm{rpm}$ devrinde 5 dakika boyunca döndürme kuvvetine maruz bırakılmıştır. Ağzı kapalı karışım kabında uygulanan bu karıştırma işlemi ile numune içinde bulunan petrol damlacıkları birbiri ile çarpıştırılıp yapışması sağlanmıştır. Birbirine yapışan bu damlacıkların hacmi kütlesine göre daha çok arttığından yoğunluğu azalmış ve suyun yüzeyinde birikmeye başlamıştır. 5 dakikalık karıştırma işleminden sonra her bir numune 18 saat boyunca dinlendirilmiştir. 
$\mathrm{Bu}$ işlem sonucunda da suyun içinde bulunan tüm petrol damlacıklarının yüzeye çıkıp suyun da tamamen dibe çökmesi sağlanmış olup daha sonra mezürdeki ilgili değer ölçülmüştür. Numunenin ayrışma sistemine girmeden önceki petrol/su oranı ile ayrışma sonrası petrol/su oranı karşılaştırılıp ayrışma verimlilik değeri hesaplanmıştır. Manyetik karıştırıcı ile yapılan çalışma sonucu ölçülen değerlerin bir örneği şekil 4'de gösterilmiştir.

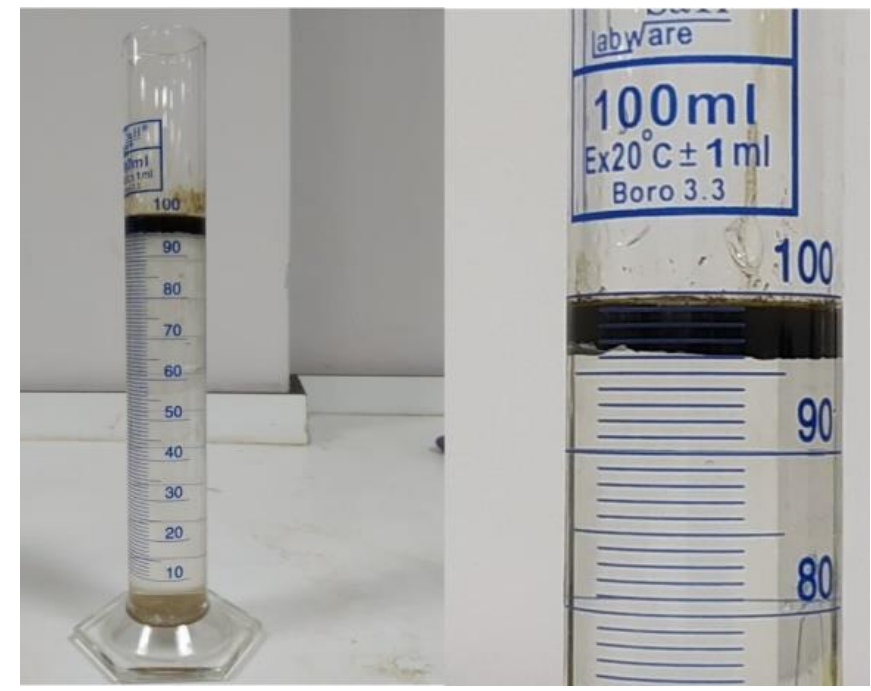

Şekil 4. Ayrışma sonucu yapılan ölçüm örneği

Şekil 4'de de görüldüğü üzere daha önce bahsedilen işlemlerden geçirilen petrol-su karışımındaki su, tamamen dibe çöküp içindeki tüm petrol damlacıkları da yüzeyde toplanmaktadır. Numune 1 kullanılarak bu yöntemle yapılan ölçümler neticesinde elde edilen ayrışma verimlilik değerleri ve Re sayısı ile karşılaştırılması şekil 5'de verilmiştir. Şekilden de görüleceği üzere başlangıçta $(\mathrm{Re}=0) \% 91$ su içeren petrol-su karışımının ayrışma sistemine 3 farklı Re sayısı $(1557.73,2180.82,2803.92)$ için elde edilen ayrışma verimlilik değerleri incelendiğinde Re sayısının 2180.82 olduğu durumda en yüksek ayrışma verimliliği sağlandığı görülmektedir. Re sayısının 2803,92 (v=0.9 m/s) olması durumu için yapılan ölçüm sonucunda da \%98,5 oranında su içerdiği görülmüş olup Re sayısının artması ile ayrışma verimliliğinin düştüğü gözlemlenmiştir.

Numune 2 için yapılan analiz sonuçları şekil 5'de görülmektedir. Başlangıçta \%90 su içeren petrol-su karışımı 3 farklı hız değerinde $(0.5,0.7,0.9 \mathrm{~m} / \mathrm{s})$ ayrışma sistemine pompalandığında en yüksek ayrışma verimliliğinin $0.7 \mathrm{~m} / \mathrm{s}$ hız ve 2346,37 Re sayısı değerinde elde edildiği görülmektedir. Petrol-su karışımının hızı $0.9 \mathrm{~m} / \mathrm{s}$ olarak ayarlandığında ayrışma verimlilik değerinde düşüş gözlenmiş olup ayrışma sonucu elde edilen karışımın içindeki petrol-su oranı \% 97,75 olarak ölçülmüştür. Bunun sonucunda da Re sayısı arttıkça laminer akıştan türbülanslı akışa doğru geçiş olurken ayrışma verimlilik değerinin düştüğü gözlemlenmiştir. Ayrışmada kullanılan delikli birleştirilmiş plaka setlerinin uzunluğu $800 \mathrm{~mm}$ olduğundan belli bir hız değerine kadar ayrışma sağlanırken hız değerinin yükseltilmesi ayrışma verimliliğinde düşüşe sebep olmaktadır.

En az su içeren (\%89) ve viskozitesi en düşük (5.7 x 10-3) olan Numune 3 için yapılan ayrışma sonucu elde edilen ayrışma verimlilik değerleri şekil 5'de görülmekte olup Re sayısı-karışımdaki su oranı arasındaki ilişki irdelenmektedir. Tüm numuneler arasında en yüksek Re sayısı $(3420,97)$ değerine sahip numune 3 için yapılan analizlerde en düşük ayrışma verimlilik değeri (\%95 su) elde edildiği görülmüştür. Bu analiz sonuçlarına bakılarak karışımın hızı arttıkça Re sayısı da artmaktadır ve bununla birlikte ise akışkan karışımının türbülanslılık özelliği artmakta olup ayrışma verimliliği de buna bağlı olarak düşmektedir. Tasarlanan deney düzeneğinde $800 \mathrm{~mm}$ uzunluğundaki birleştirilmiş plakalar kullanıldığından hız değeri ile ayrışma verimlilik değeri arasından belli bir hız değerine kadar doğru orantı olmakla birlikte hız değerinin sürekli arttırılmasının sonucunda ayrışma verimlilik değerinde de düşüş gözlemlenmektedir. 


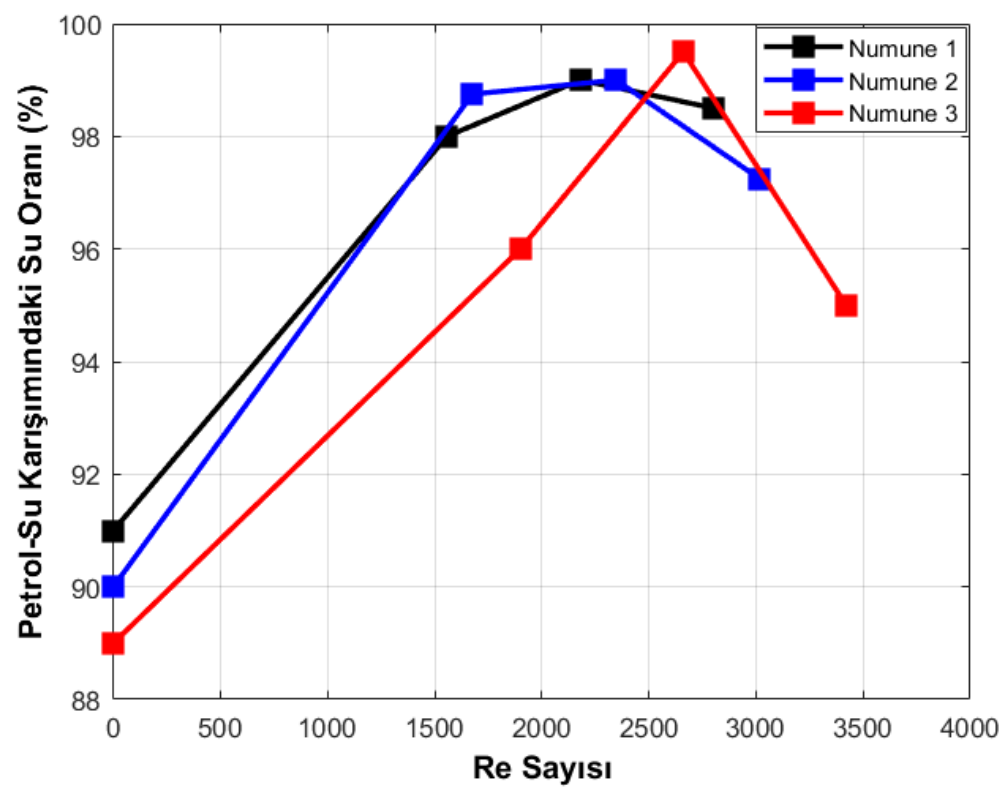

Şekil 5. Kullanılan bütün numunelere ait ayrışma verimlilik değerlerinin karşılaştırılması

Yapılan deneylerden elde edilen tüm ayrışma verimlilik sonuçları şekil 5'de gösterilmektedir. İlgili şekilden de görüleceği üzere en yüksek ayrışma verimlilik değeri \%11 oranında petrol içeren Numune 3 ve 0.7 m/s pompalanma hızında, \% 99.5 olarak ölçülmüştür. Ayrıca ilgili şsekilden de görüleceği üzere en düşük ayrışma verimlilik değeri de numune için $0.9 \mathrm{~m} / \mathrm{s}$ pompalanma hızında $\% 95$ olarak elde edilmiştir. En yüksek ve en düşük ayrışma verimlilik değerinin en yüksek oranda petrol içeren karışımdan elde edilmesi ayrışma için en uygun hız değerinin ne kadar önemli olduğunu ortaya koymaktadır. Birleştirilmiş plaka kullanılarak gerçekleştirilen ayrışma sistemlerinde en önemli nokta, pompalanan akışkanı mümkün olduğunca birleştirilmiş plakalar ile temas ettirmek ve akış yapısında değişiklik meydana getirip birleştirilmiş plakadaki delikler etrafında akış ayrılma noktaları oluşturmaktır. Birleştirilmiş plakaların delikleri etrafında akış yapısı değişmekte olup delikler etrafında ayrılma noktaları (seperation point) oluşmaktadır. Oluşan bu ayrılma noktaları sayesinde de petrol damlacıkları birbiriyle daha fazla etkileşime geçip damlacıkların birbirine yapışma ihtimali artmaktadır. Birbirine yapışan damlacıklar da yüzeye rahatça çıkabilmektedir.

Gerçekleştirilen bir dizi çalışma neticesinde ham petrol ve ayrışmış yeraltı suyu elde edilmiştir. Elde edilen ham petrol, rafinerilerde bir dizi ön işlemden geçirilip ayrımsal damıtma sürecine tabi tutulur. Ayrımsal damıtma neticesinde ise, ham petrolün çıkarıldığı bölgeye göre farklılık göstermekle beraber asfalt, fuel-oil, mazot, benzin elde edilmektedir. Ham petrolden ayrışan su ise içerdiği mineraller (kükürt ve türevleri) bakımından tarımda veya herhangi bir sektörde kullanılamamaktadır. Ham petrolün üretildiği bölgede yer altından ham petrol ve su çekildiği için ilgili bölgede yer altında ciddi boşluklar meydana gelmektedir. Oluşan bu boşluklar da ilerleyen zamanlarda toprak çökmelerine neden olmaktadır. Bu nedenle elde edilen ayrışmış su, petrol sondajının yapıldığı bölgede özel olarak sondajı yapılan enjeksiyon kuyuları vasıtasıyla tekrar yer altına basılmaktadır.

\section{TEŞEKKÜR}

Bu çalışma Van Yüzüncü Yıl Üniversitesi Bilimsel Araştırma Projeleri Koordinatörlüğü tarafından FOA-2019-7591 numaralı proje ile desteklenmiştir. 


\section{SONUÇLAR}

İlgili çalışma kapsamında Adıyaman-Batman ve Diyarbakır'da bulunan petrol sahalarından alınan farklı özelliklere sahip petrol numuneleri 3 farklı hız değerinde ayrışma sistemine pompalanıp her bir numune için ayrışma verimliliği irdelenmiştir. Gerçekleştirilen tüm deneylerde farklı ayrışma verimlilik değerleri elde edilmiş olup bu ayrışma verimlilik değerlerine bakılarak ulaşılan sonuçlar;

- Akışkan karışımının hızı artıkça karışımın ayrışma verimliliği de belli bir noktaya kadar artarken daha yüksek hız değerlerinde ayrışma verimlilik değerinin düştüğü gözlemlenmiştir. Bu düşüşün de sisteme giren karışımın; hızının artmasından dolayı daha kısa sürede sistemi terk etmesinden ve delikli birleştirilmiş plakalar ile etkileşime girememesinden kaynaklandığı sonucuna varılmıştır. Karışımın hızının yüksek olmasından dolayı akışkanın büyük bir kısmı birleştirilmiş plaka yüzeyi ile temas etmemekte olup birleştirilmiş plaklarda bulunan kavislerin, deliklerin akışkan karakteristikleri üzerindeki etkisi azalıp ayrışma verimliliği de düşmektedir.

- Ayrışma sistemine yüksek hızda giren akışkan karışımının; birleştirilmiş plakalar ile temas ettiği noktadan itibaren ayrışma başlamakta olup birbirine yapışan petrol damlacıkları da deliklerden yukarı doğru hareket etmektedir. Yüksek hızdaki karışım, bu petrol damlacıklarının yüzeye doğru çıkma süresini geciktirmekte olup ayrışma sisteminin çıkış noktasına doğru sürüklemektedir. Sistemin çıkış noktasına gelen akışkan karışımının içinde bulunan petrol damlacıkları birbirine yapışmış olsa bile yüksek hızdan doğan kuvvetin etkisiyle yüzeye çıkamamakta ve ayrışış su ile birlikte tahliye olmaktadır.

- Ayrışma sistemine pompalanan karışımın ayrışma verimliliğini etkileyen parametrelerden biri de kullanılan petrol-su karışımının yoğunluğudur. İçinde \%89 su bulunan karışımın sisteme yollanmasıyla yapılan tüm deneyler arasında en yüksek ayrışma verimlilik değerinin $(\% 99,5)$ elde edildiği görülmüş̧ür. Karışımın petrol oranı yüksek olduğundan petrol damlacıkları daha hızlı bir şekilde etkileşime geçip birbirine kolayca yapışabilmektedir. Ancak diğer taraftan $0.9 \mathrm{~m} / \mathrm{s}$ hız ile sisteme pompalanan aynı numuneye bakıldığında tüm deneyler arasından en düşük ayrışma verimlilik değerinin $\% 95$ olarak elde edildiği görülmüştür. Yüksek oranda petrol içeren (\%11) karışımın kullanılıp sisteme $0.9 \mathrm{~m} / \mathrm{s} \mathrm{hız} \mathrm{değerinde} \mathrm{pompalanması} \mathrm{sırasında} \mathrm{petrol} \mathrm{damlacıklarının} \mathrm{birleştirilmiş} \mathrm{plakaların} \mathrm{yarısından}$ $(400 \mathrm{~mm})$ sonra yüzeye çıktığı görülmüştür.

Sonuç olarak ayrışma verimlilik değerinin akışkanın sisteme pompalanma hızı ve karışımdaki petrol oranına bağlı olarak değiştiği gözlemlenmiştir. Akış karakteristiklerinden ve karışımın birleştirilmiş plakalar ile etkileşime geçebilmesinden dolayı ayrışma verimliliği değişmektedir. Ayrışma verimliliği ve karışımın sisteme pompalanma hızı arasındaki optimum bağlantı belirlenmiş olup buna bağlı olarak maksimum ayrışma verimlilik değeri belirlenmiştir.

\section{KAYNAKÇA}

[1] Hashim, R, Abdolhamid, A., Mars, E. (2009). Evaluation of Bio-Surfactants Enhancement on Bioremediation Process Efficiency for Crude Oil Contaminated Soil at Oilfield. Strategic Study, 20, 2530 .

[2] John, A., Veil, Markus G., Puder, Elcock D., Robert J., Redweik, J. (2004). A White Paper Describing Produced Water from Production of Crude Oil. Natural Gas and Coal Bed Methane produced water, P0401pdf. 
[3] Zhaohui, X., Ashok, M., Wilfred, C. (2003). Detection of Benzene, Toluene, Ethylbenzene, and Xylenes (BTEX) Using Toluene Dioxygenase-Peroxidase Coupling Reactions. Biotechnology Progress, 19(6), 1812-1815.

[4] Agency USEP. (1998). National Center for Environmental Assessment-Washington Office of Research and Development. Carcinogenic Effects of Benzene: An Update, Washington DC., 57.

[5] Reusser, DE., Field, JA. (2002). Determination of Benzyl Succinic acid in Gasoline-Contaminated Ground Water by Solid-Phase Extraction Coupled with Gas Chromatography. Mass Spectrometry, 953, 215-225.

[6] Gu, Y. (2001). Separation of Produced Petroleum Fluids Using a Coalescer Column. Research Proposal Submitted to Petroleum Technology Research Centre (PTRC).

[7] Rao, TC., Patil, DP. (1998). Developments in Gravity Separation, J. Mines Metals \&Fuels, 46, 383.

[8] Ruiz, MC., Padilla, R. (1996). Separation of Liquid-Liquid Dispersion in a Deep-Layer American Chemical Society Gravity Settler, Part II Mathematical Modeling of the Settler, Hydrometallurgy, 42, 281 .

[9] Kenawy, FA., Kandil, ME., Aboarab, TW. (1997). Produced Water Treatment Technology-A Study of Oil/Water Separation in Gravity-type Cross flow Pack Separators for Qualitative Separation, SPE Prod. \& F acil, 12, 112.

[10]Morrison, J. (1970). Tilted Plate Separators for Refinery Wastewater, Oil and Gas Journal, 68(50), 8086.

[11]Kok, DF., Marson, HW. (1978). Tanker Ballast Water Meets Through Treating Specs, Oil and Gas Journal, 76(49), 7-92.

[12]Mohr, KS. (1993). A New Type of High Efficiency Oil-Water Separator for Better Water Quality Management, Submitted to The Faculty of The Graduate College of The Oklahoma State University in Partial Fulfillment of The Requirements for The Degree of Master of Science. December, 1993.

[13]Algifri, AH., Bhardwaj, RK., Rao, YVN. (1988). Turbulence Measurements in Decaying Swirl Flow in A Pipe. Applied Scientific Research, January 1988, 45, 233-250.

[14]Escobar, OM. (2005). The Graduate School Performance Evaluation of Modified Liquid-Liquid Cylindrical Cyclone. Petroleum Engineering the Graduate School the University of Tulsa.

[15]Guerin, TF. (2002). Heavy Equipment Maintenance Wastes and Environmental Management in The Mining Industry. J. Environ. Manage, 66, 185-199.

[16] Yayla, S., Olcay, A.B., Ibrahim, S.S. (2017). Numerical Investigation of Coalescing Plate System to Understand the Separation of Water and Oil in Water Treatment Plant of Petroleum Industry, Engineering Applications of Computational Fluid Mechanics, 11(1), 184-192.

[17]Perry JH, Perry RH, Chilton CH, Kirkpatrick SD. (1963). Chemical Engineers Handbook (4 Ed)., McGraw-Hill Book Company, New York, NY. 